\title{
Systematic review of the effect of processing of whole-grain oat cereals on glycaemic response
}

\author{
Susan M. Tosh ${ }^{1 *}$ and YiFang $\mathrm{Chu}^{2}$ \\ ${ }^{1}$ Agricultural and Agri-Food Canada, Guelph, ON, Canada N1G 5 C9 \\ ${ }^{2}$ Quaker Oats Center of Excellence, PepsiCo RED Nutrition, Barrington, IL 60010, USA \\ (Submitted 12 December 2014 - Final revision received 29 June 2015 - Accepted 30 June 2015 - First published online 2 September 2015)
}

\begin{abstract}
Whole-grain oats have been identified as a type of food that blunts blood glucose increase after a meal. However, processing of oats changes the physical characteristics of the grain, which may influence human glycaemic response. Therefore, the effect of different processes on acute postprandial glycaemic response, quantified using glycaemic index (GI) measurements, was investigated in a systematic review. A review of the literature identified twenty publications containing fifty-six individual tests. An additional seventeen unpublished tests were found in an online database. Of the seventy-two measurements included in the review, two were for steel-cut oats, eleven for large-flake oats, seven for quick-cooking (small flake) oats, nine for instant oatmeal and twenty-eight for muesli or granola. One granola measurement was identified as an outlier and was removed from the statistical analysis. In all, fifteen clinical tests were reported for rolled oat porridge that did not specify the type of oats used, and thus the effect of processing could not be assessed. Steel-cut oats (GI = 55 (SE 2.5)), large-flake oats (GI = 53 (SE 2.0)) and muesli and granola $(\mathrm{GI}=56$ (SE 1.7)) elicited low to medium glycaemic response. Quick-cooking oats and instant oatmeal produced significantly higher glycaemic response ( $\mathrm{GI}=71$ (SE $2 \cdot 7$ ) and 75 (SE 2.8), respectively) than did muesli and granola or large-flake oatmeal porridge. The analysis establishes that differences in processing protocols and cooking practices modify the glycaemic response to foods made with whole-grain oats. Smaller particle size and increased starch gelatinisation appear to increase the glycaemic response.
\end{abstract}

Key words: Oats: Glycaemic response: Glycaemic index: Processing: Whole grains

Oats have a long tradition of use in food ${ }^{(1)}$, and oatmeal porridge is widely recognised as an inexpensive, healthy food $^{(2,3)}$. Unlike wheat, this cereal grain is usually consumed in whole-grain form. Oats are higher in protein, Ca and essential fatty acids than are other grains ${ }^{(2)}$. Oats are also high in dietary fibre, including soluble fibre, mixed linkage $\beta$-glucan, which has been shown to reduce serum cholesterol, a risk factor for $\mathrm{CHD}^{(4)}$. Although a number of oat products are available commercially, oatmeal for porridge and ready-to-eat cereals, such as muesli and granola, remain the most popular oat-based consumer products in the market ${ }^{(3)}$.

Oats for making hot cereal are available in different forms, including steel-cut oats, large-flake oats, quick-cooking oats and instant oatmeal. Oat flakes are also used to make muesli and granola cereal, generally eaten cold. Because these products have different physical characteristics, it is important to know whether different processing protocols applied to whole-grain oat products affect their nutritional properties. There is evidence that whole-grain oats have the ability to lower postprandial blood glucose $\mathrm{e}^{(5)}$, and it is of interest to know whether this property is affected by processing.
Oat milling conditions are modified to produce a range of characteristics. After dehulling, oats are kilned to inactivate enzymes and develop the typical nutty, toasted flavour. Kilning is a steam heating process followed by drying and cooling ${ }^{(6)}$. Steel-cut oats are produced by cutting the groats into two to four pieces laterally. Oat flakes are made by passing whole groats, which have been tempered or steamed, between a pair of rollers ${ }^{(6)}$. The gap between the rollers determines the thickness of the flakes ${ }^{(7)}$. Thick oat flakes, also called oldfashioned, traditional or jumbo flakes, are made using a wider gap compared with thin oat flakes, generally referred to as quick oatmeal. The smaller flake size of quick oats means that they require a shorter cooking time ${ }^{(6)}$. Instant oatmeal is made from steel-cut oats that have been kilned at a higher temperature than normal steel-cut oats to partially gelatinise the $\operatorname{starch}^{(6)}$. The rollers are set close together to produce thin flakes. This milling process enables instant oatmeal to hydrate quickly in boiling water ${ }^{(3)}$. Muesli and granola are wholeoat-flake cereals that usually include a variety of dried fruit, nuts and seeds, and are generally eaten without further cooking ${ }^{(7)}$. Muesli is generally produced from large or small oat flakes

Abbreviation: GI, glycaemic index.

* Corresponding author: Dr S. M. Tosh, email Susan.Tosh@AGR.GC.CA 
without further treatment, whereas granola is usually made by toasting the oat flakes ${ }^{(7)}$.

Processing and preparation of food products has the potential to change the structure of food products and the characteristics of the $\operatorname{starch}^{(8)}$. The shear between the rollers during milling breaks cell walls and increases the bio-accessibility of starch by digestive enzymes. Combined heat and moisture treatments during kilning and cooking cause partial or complete disruption of the starch granules in oats ${ }^{(9)}$. Cooking or steaming allows water to be absorbed into the starch granules so that they swell and solubilise the starch molecules. This open structure allows digestive enzymes to penetrate the starch more easily, increasing the rate of breakdown. Thorough cooking can cause the starch granules to be completely disrupted; this process is called gelatinisation ${ }^{(10)}$. Soluble starch is released and becomes very susceptible to enzymatic degradation. Thus, the effects of processing on whole-grain oat foods may affect starch digestibility and the glycaemic response.

Glycaemic index (GI) is a classification of the blood glucoseraising potential of carbohydrate foods ${ }^{(11)}$. It is defined as the incremental area under the blood glucose response curve elicited by a $50 \mathrm{~g}$ available carbohydrate portion of a food expressed as a percentage of that after $50 \mathrm{~g}$ carbohydrate from a reference food taken by the same subject' ${ }^{(11)}$. Because GI is a property of an individual food, it is useful for assessing the effects of processing

The objective of the current review was to compare the GI of different whole-grain oat food products to determine whether milling and cooking practices influence the glycaemic response of humans. Differences between products were discussed in terms of composition, processing history and product characteristics that influence starch digestibility.

\section{Methods}

A preliminary search showed that GI was the most commonly used indicator of glycaemic response for whole-oat foods; therefore, GI was used as a standardised value to make comparisons between products. To be eligible for inclusion into the investigation the studies had to be clinical trials performed in human subjects in which GI had been measured or could be calculated by means of the standardised method from available data ${ }^{(6)}$. Food items made with whole-grain oats in which oat was the only or main ingredient, such as oat porridges, granola and muesli, were included. Food items in which oat bran or oat extracts were the main ingredient were not included.

PubMed and Scopus search engines were searched for original journal articles on 8 December 2014. The search string was ((oat or oats or oatmeal or porridge or granola or muesli) and (glycemic index or glycaemic index)). The screening process is outlined in Fig. 1. PubMed returned sixty-four results, whereas Scopus returned ninety-nine. After elimination of duplicates 106 articles remained. Of these articles, which were reviewed by title and abstract, thirteen were eliminated because they were not clinical trials conducted in human subjects, and thirty-six of the identified articles did not use acceptable methodologies. Many were longer term studies (up to 12 weeks) that did not measure postprandial blood glucose, used mixed meals, did not include a control, or involved vigorous exercise during testing. A total of twenty-eight of the identified articles did not include oats or use whole-grain oats. In all, eighteen articles were studies that used food items that were not mainly oats, such as bread and cookies.

A total of eleven clinical trials met the criteria for inclusion. A total of nine other journal articles were also identified during the review process in the reference lists and were included $^{(23 ; 24 ; 25 ; 26 ; 27 ; 28 ; 29 ; 30 ; 31) . ~}$

The Glycemic Index ${ }^{(12)}$ website managed by The University of Sydney was consulted for unpublished results. Searches were conducted individually for oats, oatmeal, porridge, granola and muesli. A total of thirteen products were found that had been tested by the Glycemic Index Research Service of Sydney University ${ }^{(12)}$. One product was tested by the International Diabetes Institute ${ }^{(13)}$, and three results were from Glycemic Index Laboratories Inc. ${ }^{(14)}$. These independent testing laboratories were considered reliable sources of information, and the data were included in the review.

Data extracted from the publications included product type, GI with the standard error, available carbohydrates per serving, and the number and health status of subjects. When GI was calculated using white bread $=100$, the data were recalculated on a glucose $=100$ basis. The GI did not need to be calculated from AUC data in any of the articles. Descriptions of the products, cooking protocols and $\beta$-glucan content were also collected to be used in discussion of differences in glycaemic response.

Some of the publications identified the type and source of rolled oats and the cooking method, but others did not. If the type of oat was ambiguous, but the cooking method was provided, oats that were cooked in $5 \mathrm{~min}$ or less were considered quick oats; and oats cooked in 10 min or more were considered large-flake oats. Other authors only indicated statements like 'oats cooked according to the package directions' or had no information; these were put in a separate group called 'rolled oats' to allow statistical evaluation.

Statistical analysis was performed with Prism 5 (2007) by GraphPad Software Inc. (www.GraphPad.com). The D'AgostinoPearson omnibus normality test was performed to ensure that the groups were normally distributed. The mean values, standard errors and number of subjects of each test were used to conduct a one-way ANOVA and calculate the grand mean and overall standard error. Tukey's multiple comparison tests were conducted to distinguish differences between treatments. The threshold for statistical significance was $P=0 \cdot 05$. Results are expressed as means with their standard errors for individual tests and as grand means with their standard error for product groups. Regression analysis was performed to detect possible effects of available carbohydrate dose on GI measurements.

\section{Results}

A total of seventy-two measurements were found from twenty publications and three independent laboratories. Table 1 


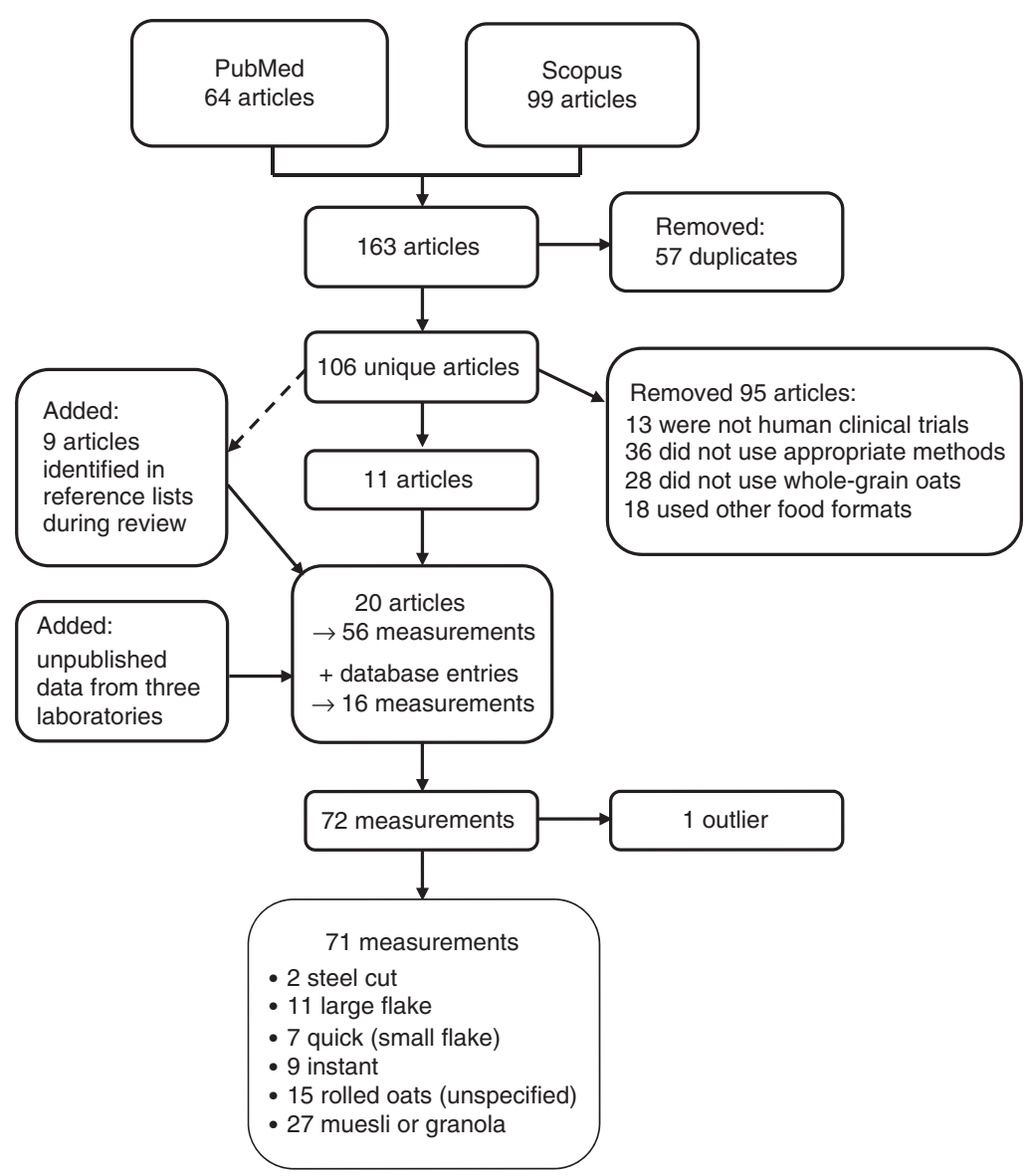

Fig. 1. Flow diagram of the study screening and evaluation process.

summarises the results by product category. Only two observations were reported for steel-cut oats, whereas there were twenty-eight measurements for muesli and granola. The number of subjects used to determine GI ranged from six to nineteen, but $88 \%$ of the measurements were recorded using eight to twelve subjects. The majority of measurements (93\%) were conducted in healthy subjects with normal glycaemic responses. The remaining five trials used type 1 and/or type 2 diabetic subjects. The $\beta$-glucan content was not reported for any of the products.

The available carbohydrates in the test meals ranged from 16 to $50 \mathrm{~g}$. Although the definition of GI stipulates the use of $50 \mathrm{~g}$ of available carbohydrate, it has been recognised that smaller amounts can be used, provided the control contains an equivalent amount of available carbohydrate ${ }^{(37)}$. To ensure that the available carbohydrate dose did not influence the result, regression analysis was performed. No significant slope was detected for large-flake $(P=0 \cdot 11)$, quick $(P=0.65)$, instant $(P=0.43)$, unspecified rolled oats $(P=0.99)$ or granola and muesli $(P=0 \cdot 65)$, indicating that the measurements taken using different doses were comparable.

The GI values ranged from 39 to 88 , which is very large, considering that all of the products were entirely or mainly oats. The large-flake, instant, rolled oat and muesli groups passed the test of normality; however, the steel-cut and quick groups were too small to be assessed.
There were two measurements in the steel-cut oatmeal group, and the GI was 55 (SE 2.5) (range =52-57). The eleven products in the large-flake oatmeal group had an average GI of 53 (SE 2.0) (range $=40-63$ ), whereas the seven products in the quick-oatmeal group had an average GI of 71 (sE 2.7) (range $=61-80$ ). The fifteen rolled oat products in which the flake size was not given and could not be assigned to either the large or the quick groups had an average GI of 51 (SE 2.3) (range $=40-69$ ). Instant oatmeal (nine measurements) had an average GI of 75 (SE 2.8) (range $=65-88)$. One outlier was removed from the muesli and granola group, because it was more than 3 SD higher than the mean ${ }^{(21)}$. Removing this data point for a commercial muesli product (GI $=86$ (SE 10)) resulted in smaller confidence intervals. After removal of the outlier the average of the twenty-seven measurements was GI $=56$ ( $\operatorname{se~1.7)~}$ (range $=39-70$ ).

Fig. 2 shows the distribution of GI values for the different groups of products and the median. Quick oats and instant oatmeal were not significantly different from each other $(P>0.05)$. Steel-cut oats were found to be significantly different only from instant oatmeal $(P<0 \cdot 05)$. The GI of the large-flake, rolled oats (unspecified size) and the muesli/granola groups were not significantly different from each other $(P>0.05)$. Porridge made from large flakes or rolled oats (unspecified size) and muesli/granola was significantly lower in glycaemic 
Table 1. Summary of glycaemic indices (GI) for whole-grain oat products*

(Gl with their standard errors)

\begin{tabular}{|c|c|c|c|c|c|c|}
\hline Type & Description & Cooking method & GI & SE & $A C(g)$ & Subjects \\
\hline \multirow[t]{2}{*}{ Steel cut } & Porridge made from steel-cut oats cooked in water ${ }^{(12)}$ & $\mathrm{b}$ & 52 & 4 & 33 & $9 \mathrm{~N}$ \\
\hline & Old-fashioned steel-cut oats ${ }^{(12,14)}$ & $\mathrm{u}$ & 57 & 8 & 25 & $10 \mathrm{~N}$ \\
\hline \multirow[t]{11}{*}{ Large flake } & Porridge, jumbo oats, with $125 \mathrm{ml}$ semi-skimmed milk ${ }^{(15)}$ & $\mathrm{u}$ & 40 & 6 & 22 & $10 \mathrm{~N}$ \\
\hline & Porridge made from rolled oats ${ }^{(16)}$ & $\mathrm{b}$ & 49 & 8 & 23 & $6 \mathrm{~N}$ \\
\hline & Jumbo porridge oats ${ }^{(17)}$ & $\mathrm{u}$ & 50 & 12 & 25 & $12 \mathrm{~N}$ \\
\hline & Oat porridge made from roasted thick flakes ${ }^{(18)}$ & $u$ & 50 & 6 & 27 & $10 \mathrm{~N}$ \\
\hline & Traditional porridge oats made from rolled oats ${ }^{(12)}$ & $u$ & 51 & 8 & 21 & $10 \mathrm{~N}$ \\
\hline & Oat porridge made from steamed thick oat flakes ${ }^{(18)}$ & $u$ & 53 & 6 & 27 & $10 \mathrm{~N}$ \\
\hline & Oat porridge made from thick oat flakes ${ }^{(18)}$ & $u$ & 55 & 6 & 27 & $10 \mathrm{~N}$ \\
\hline & Traditional rolled oats ${ }^{(12)}$ & $u$ & 57 & 5 & 19 & $10 \mathrm{~N}$ \\
\hline & Porridge made from rolled oats ${ }^{(19)}$ & $\mathrm{b}$ & 58 & 4 & 21 & $7 \mathrm{~N}$ \\
\hline & Jungle oats with $150 \mathrm{ml}$ milk and $20 \mathrm{~g}_{\text {sugar }}(20)$ & $\mathrm{b}$ & 62 & 6 & 50 & $18 \mathrm{~N}$ \\
\hline & Porridge made from rolled oats, Scottish ${ }^{(21)}$ & $\mathrm{m}$ & 63 & 7 & 31 & $10 \mathrm{~N}$ \\
\hline \multirow[t]{7}{*}{ Quick (small flake) } & Porridge made from small oats with $125 \mathrm{ml}$ semi-skimmed milk ${ }^{(15)}$ & $\mathrm{u}$ & 61 & 6 & 22 & $10 \mathrm{~N}$ \\
\hline & Rolled oats porridge ${ }^{(22)}$ & $\mathrm{b}$ & 62 & 6 & 50 & $9 \mathrm{~N}$ \\
\hline & Oat porridge made from roasted thin oat flakes ${ }^{(18)}$ & $\mathrm{b}$ & 69 & 6 & 27 & $10 \mathrm{~N}$ \\
\hline & Bokomo oats with $150 \mathrm{ml}$ milk and $20 \mathrm{~g}_{\text {sugar }}(20)$ & $\mathrm{b}$ & 74 & 7 & 50 & $19 \mathrm{~N}$ \\
\hline & Porridge made from rolled oats ${ }^{(23)}$ & $\mathrm{b}$ & 75 & & 23 & $8 \mathrm{D}$ \\
\hline & Oat porridge made from thin flakes ${ }^{(24)(10)}$ & $\mathrm{u}$ & 76 & 7 & 25 & $12 \mathrm{~N}$ \\
\hline & Oat porridge made from roasted and steamed thin oat flakes ${ }^{(18)}$ & $\mathrm{b}$ & 80 & 6 & 27 & $10 \mathrm{~N}$ \\
\hline \multirow{9}{*}{ Instant } & Quick oats, instant porridge ${ }^{(25,26)}$ & $\mathrm{i}$ & 65 & & 26 & $6 \mathrm{D}$ \\
\hline & Instant porridge, anchovy flavour ${ }^{(27)}$ & i & 67 & 5 & 50 & $10 \mathrm{~N}$ \\
\hline & Instant porridge & $\mathrm{i}$ & 69 & 3 & 20 & $8 \mathrm{~N}$ \\
\hline & Instant porridge with $150 \mathrm{ml}$ milk and $20 \mathrm{~g} \mathrm{sugar}^{(20)}$ & i & 71 & 4 & 50 & $19 \mathrm{~N}$ \\
\hline & Instant porridge ${ }^{(25)}$ & $\mathrm{i}$ & 71 & & 24 & $10 \mathrm{D}$ \\
\hline & Instant oat porridge ${ }^{(12)}$ & $\mathrm{m}$ & 82 & 10 & 24 & $10 \mathrm{~N}$ \\
\hline & Instant oat cereal porridge ${ }^{(29)}$ & $\mathrm{i}$ & 83 & 10 & 36 & $10 \mathrm{~N}$ \\
\hline & Instant oatmeal porridge made from packet ${ }^{(28)}$ & $\mathrm{i}$ & 83 & 7 & 22 & $8 \mathrm{~N}$ \\
\hline & Instant porridge ${ }^{(17)}$ & $\mathrm{i}$ & 88 & 14 & 25 & $12 \mathrm{~N}$ \\
\hline \multirow[t]{15}{*}{ Rolled oats (unspecified type) } & Hot oat cereal with $125 \mathrm{ml}$ skimmed milk ${ }^{(29)}$ & $\mathrm{u}$ & 40 & 9 & 23 & $10 \mathrm{~N}$ \\
\hline & Hot oat cereal, cocoa flavour with $125 \mathrm{ml}$ skimmed milk ${ }^{(29)}$ & $u$ & 40 & 5 & 23 & $10 \mathrm{~N}$ \\
\hline & Porridge made from rolled oats ${ }^{(30)}$ & $\mathrm{m}$ & 42 & 4 & 21 & $7 \mathrm{~N}$ \\
\hline & Hot oat cereal, berry flavour with $125 \mathrm{ml}$ skimmed milk ${ }^{(29)}$ & $u$ & 43 & 6 & 26 & $10 \mathrm{~N}$ \\
\hline & Hot oat cereal, fruit flavour with $125 \mathrm{ml}$ skimmed milk ${ }^{(29)}$ & $u$ & 47 & 8 & 25 & $10 \mathrm{~N}$ \\
\hline & Hot oat cereal, honey flavour with $125 \mathrm{ml}$ skimmed milk $^{(29)}$ & $u$ & 47 & 8 & 26 & $10 \mathrm{~N}$ \\
\hline & Hot oat cereal with $125 \mathrm{ml}$ skimmed milk ${ }^{(29)}$ & $u$ & 47 & 6 & 23 & $10 \mathrm{~N}$ \\
\hline & Hot oat cereal, orchard fruit flavour with $125 \mathrm{ml}$ skimmed milk ${ }^{(29)}$ & $u$ & 50 & 7 & 25 & $10 \mathrm{~N}$ \\
\hline & Porridge oats made from rolled oats ${ }^{(12,13)}$ & $\mathrm{u}$ & 50 & 4 & 19 & $12 \mathrm{~N}$ \\
\hline & Porridge made from rolled oats $(28)$ & $\mathrm{u}$ & 55 & 2 & 23 & $9 \mathrm{~N}$ \\
\hline & Porridge made from rolled oats ${ }^{(31)}$ & $u$ & 58 & 9 & 21 & $10 \mathrm{~N}$ \\
\hline & Porridge made from oats ${ }^{(32)}$ & $u$ & 46 & & 50 & $12 \mathrm{~N}$ \\
\hline & Porridge made from rolled oats ${ }^{(21)}$ & $\mathrm{m}$ & 63 & 11 & 29 & $8 \mathrm{~N}$ \\
\hline & Porridge, organic made from rolled oats ${ }^{(21)}$ & $\mathrm{m}$ & 63 & 15 & 30 & $8 \mathrm{~N}$ \\
\hline & Porridge made from rolled oats ${ }^{(33)}$ & $\mathrm{b}$ & 69 & 6 & 23 & $6 \mathrm{D}$ \\
\hline \multirow[t]{28}{*}{ Muesli and granola } & Muesli, gluten-free with $125 \mathrm{ml} 1.5 \%$ fat milk $^{(12)}$ & $\mathrm{n}$ & 39 & 6 & 19 & $9 \mathrm{~N}$ \\
\hline & Muesli, natural ${ }^{(12)}$ & $\mathrm{n}$ & 40 & 6 & 19 & $10 \mathrm{~N}$ \\
\hline & Muesli, toasted ${ }^{(34)}$ & $\mathrm{n}$ & 43 & 4 & 17 & $8 \mathrm{~N}$ \\
\hline & Granola, superfoods granola ${ }^{(17)}$ & $\mathrm{n}$ & 44 & 13 & 50 & $12 \mathrm{~N}$ \\
\hline & Muesli, café-style fibre-rich ${ }^{(12)}$ & $\mathrm{n}$ & 48 & 6 & 19 & $10 \mathrm{~N}$ \\
\hline & Muesli, natural Bircher ${ }^{(12)}$ & $\mathrm{n}$ & 48 & 5 & 22 & $10 \mathrm{~N}$ \\
\hline & Muesli, gluten-free ${ }^{(12)}$ & $\mathrm{n}$ & 49 & 3 & 22 & $10 \mathrm{~N}$ \\
\hline & Muesli, wheat-free with $125 \mathrm{ml}$ semi-skimmed milk ${ }^{(15)}$ & $\mathrm{n}$ & 49 & 6 & 19 & $10 \mathrm{~N}$ \\
\hline & Muesli, classic fruit and nut ${ }^{(12)}$ & $\mathrm{n}$ & 50 & 5 & 24 & $10 \mathrm{~N}$ \\
\hline & Muesli, Swiss Bircher ${ }^{(12)}$ & $\mathrm{n}$ & 52 & 5 & 17 & $10 \mathrm{~N}$ \\
\hline & Muesli, lite ${ }^{(31)}$ & $\mathrm{n}$ & 54 & 12 & 18 & $10 \mathrm{~N}$ \\
\hline & Original muesli, made from steamed rolled oats with dried fruit and nuts ${ }^{(35)}$ & $\mathrm{n}$ & 55 & 10 & 19 & $14 \mathrm{~N}$ \\
\hline & Muesli, Swiss formula ${ }^{(34)}$ & $\mathrm{n}$ & 56 & 8 & 16 & $8 \mathrm{~N}$ \\
\hline & Muesli, natural ${ }^{(31)}$ & $\mathrm{n}$ & 57 & 9 & 19 & $10 \mathrm{~N}$ \\
\hline & Muesli, fruit and nut ${ }^{(21)}$ & $\mathrm{n}$ & 59 & 11 & 18 & $8 \mathrm{~N}$ \\
\hline & Muesli, original, with $125 \mathrm{ml}$ semi-skimmed milk ${ }^{(15)}$ & $\mathrm{n}$ & 60 & 6 & 19 & $10 \mathrm{~N}$ \\
\hline & Muesli, Swiss with 125 ml semi-skimmed milk ${ }^{(15)}$ & $\mathrm{n}$ & 60 & 6 & 19 & $10 \mathrm{~N}$ \\
\hline & Muesli, breakfast cereal ${ }^{(25)}$ & $\mathrm{n}$ & 60 & 8 & 18 & $9 \mathrm{D}$ \\
\hline & Muesli, natural-style original Swiss ${ }^{(12)}$ & $\mathrm{n}$ & 62 & 6 & 18 & $9 \mathrm{~N}$ \\
\hline & Granola clusters breakfast cereal, original low fat ${ }^{(12,14)}$ & $\mathrm{n}$ & 63 & 4 & 22 & $10 \mathrm{~N}$ \\
\hline & Muesli, light, mixed berry and apple flavour ${ }^{(12)}$ & $\mathrm{n}$ & 64 & 7 & 20 & $10 \mathrm{~N}$ \\
\hline & Muesli, blueberry ${ }^{(36)}$ & $\mathrm{n}$ & 64 & 6 & 50 & $10 \mathrm{~N}$ \\
\hline & Muesli, plain rolled oats ${ }^{(22)}$ & $\mathrm{n}$ & 65 & 5 & 50 & $9 \mathrm{~N}$ \\
\hline & Muesli, toasted with nuts ${ }^{(21)}$ & $\mathrm{n}$ & 65 & 5 & 17 & $10 \mathrm{~N}$ \\
\hline & Muesli ${ }^{(16)}$ & $n$ & 66 & 9 & 24 & $6 \mathrm{~N}$ \\
\hline & Muesli, fruit ${ }^{(21)}$ & $n$ & 67 & 7 & 21 & $10 \mathrm{~N}$ \\
\hline & Granola clusters cereal, raisin and almond, low fat ${ }^{(12,14)}$ & $\mathrm{n}$ & 70 & 7 & 22 & $10 \mathrm{~N}$ \\
\hline & Muesli $^{(29)}$ & $\mathrm{n}$ & $86 \dagger$ & 10 & 21 & $10 \mathrm{~N}$ \\
\hline
\end{tabular}

AC, available carbohydrate; b, boiled; $N$, normal patient; $u$, unknown (not specified); $m$, microwave; $D$, diabetic patient; $i$, prepared with boiling water; $n$, no further cooking.

* Product groups are steel-cut oats, large-flake oats, quick oats, rolled oats (type not specified) and muesli and granola. Description of cooking method, Gl and sE, serving size, amount of $A C$ per serving and the number and type of subject ( $N$ or $D)$ used in the trial.

† Outlier removed from statistical analysis. 


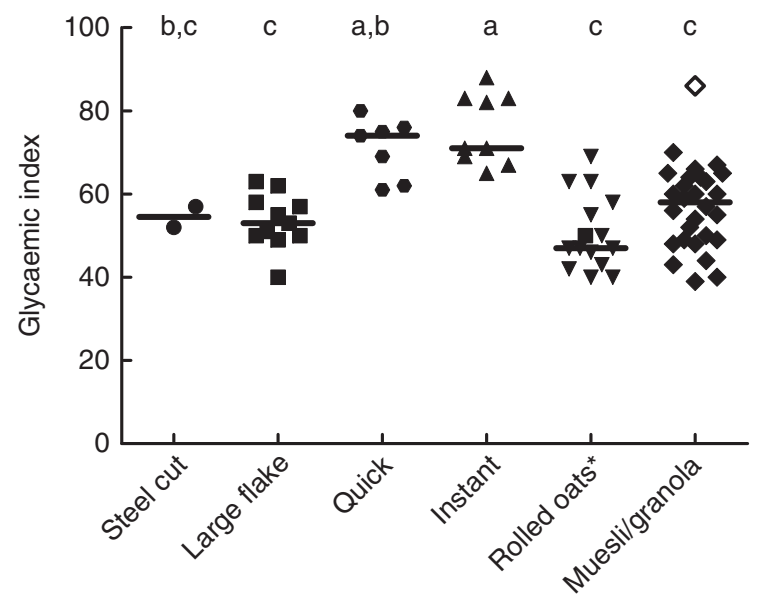

Fig. 2. Glycaemic responses to different types of whole-grain oat products. Individual measurements are indicated with the median value. ${ }^{a, b, c}$ Columns with the same letter above them are not significantly different. * Rolled oats refer to treatments where the type of oat was not specified. $\diamond$ Outlier removed from the statistical analysis.

response than were the quick and instant oatmeal porridges ( $P<0.001$ for all pair-wise comparisons).

\section{Discussion}

We observed a broad distribution of glycaemic responses to whole-grain oat products. This range is most probably a result of differences in processing. The whole-grain oatmeal porridges differed only in the way they were milled and cooked. The amounts of protein, lipids and $\beta$-glucan in the oat foods would be approximately the same with minor variations due to variety and environmental conditions ${ }^{(38)}$. Therefore, differences in composition cannot explain the differences observed.

The cooking method for the oatmeal porridges varied. Some porridges were cooked by boiling for 1-15 min, whereas others were microwaved (Table 1). Many of the authors did not specify the cooking method. There were insufficient data points in all of the categories to perform statistical analysis of whether the cooking method affected the GI. An investigation of the effect of microwaving $v$. boiling ${ }^{(10)}$ showed that there was no significant difference in the amount of starch released after 1 min of cooking for either thin- or thick-flake oatmeal. However, after $20 \mathrm{~min}$ of boiling, significantly less starch was released than during microwave cooking, because there was less cell wall disruption.

The available carbohydrate in oat foods is derived predominantly from starch, with the remainder coming from added and endogenous sugars ${ }^{(39)}$. In the native oat groat, the starch granules are surrounded by cell walls within the dense endosperm structure $^{(8)}$. In steel-cut oats, in which there is minimal disruption of groat tissue, the starch remains encased within the cell walls, except at the exposed surfaces ${ }^{(8)}$. Compared with other oats, steel-cut oats require a longer cooking time to gelatinise the starch. The GI of steel-cut and large-flake oats was 55 ( $\mathrm{SE} 2 \cdot 5$ ) and 53 (SE 2.0), respectively, suggesting that the integrity of the groat structure reduces the susceptibility of the starch to digestive enzymes ${ }^{(18,35)}$.

Quick oats and instant oatmeal have more pre-gelatinised starch and a small particle size ${ }^{(18)}$. The processing steps that allow the oatmeal to hydrate quickly in boiling water also appear to increase the glycaemic response. Digestive enzymes easily penetrate the swollen starch granules that are exposed on the large surface area. The increased susceptibility to enzymatic degradation likely accounts for the relatively high glycaemic responses of quick $(\mathrm{GI}=71(\mathrm{se} 2 \cdot 7))$ and instant $(\mathrm{GI}=75$ (sE 2.8)) oatmeal porridges.

The GI of the rolled oat group, where no indication was given of whether they were large-flake or quick oats, was 51 (sE 2.3). From the distribution of the data (Fig. 2), it would appear that many of the tests used large-flake oats. Comparisons of the groups show that the rolled oat group is not significantly different from the large-flake group $(P>0.05)$. It is unfortunate that these fifteen tests of rolled oat porridges could not be assigned to their appropriate category to increase the power of the analysis.

Muesli and granola are common food items made with oat flakes and are eaten without further cooking. The average GI value for muesli and granola was 56 (SE 1.7). The range of GI values for muesli and granola was larger than that of other oat products (39-70), probably because of the variability in formulation. Considering the ingredients used in muesli and granola, the values were as expected. Uncooked rolled oats alone have a GI of $59(\mathrm{SE} 4)^{(12)}$. Raisins and other dried fruits, the commonly added ingredients, show low to medium GI values $(30-65)^{(12,25)}$. Sugar is often added to commercial products (GI of sucrose $=68$ (SE 5)) but does not appear to have had a large effect on the GI of these products ${ }^{(40)}$. The lack of cooking to gelatinise the starch and open up the flake structure appears to maintain the glycaemic response in the low to medium range. The GI for muesli and granola (Fig. 2) was not significantly different from that of porridges made from steel-cut and large-flake oats $(P>0 \cdot 05)$.

\section{Conclusions}

Milling and cooking practices appear to produce significant changes in the digestibility of starch in oatmeal products. Glycaemic response to porridges made from steel-cut and large-flake oats was significantly lower than that for instant oatmeal. The difference is probably related to the smaller particle size, increased degree of physical disruption of the groat structure during milling and increased starch gelatinisation during the production and cooking of oatmeal. Granola and muesli products had a large range of glycaemic responses, but on average the GI was significantly lower than that of quick and instant oatmeal porridges. This may be because they are not heated in excess water, limiting starch gelatinisation. Steel-cut and large-flake hot oatmeal porridges, muesli and granola consistently demonstrate medium to low glycaemic responses, making them good options for people who are concerned about blood glucose response to foods. 


\section{Acknowledgements}

This research received no specific grant from any funding agency, commercial or not-for-profit sectors.

S. M. T. conducted literature search, reviewed identified articles, conducted statistical analysis, wrote first draft of manuscript and participated in editing of manuscript. Y. C. contributed to writing and editing of the manuscript.

S. M. T. (AAFC) has received funds from PepsiCo Inc., DSM Nutritional Products Ltd and Pulse Canada for research and publications. Y. C. is a full-time employee of PepsiCo Inc., which owns Quaker brands. The views expressed in this manuscript are those of the authors and do not necessarily reflect the position or policy of PepsiCo Inc.

\section{References}

1. Butt MS, Tahir-Nadeem M, Khan MKI, et al. (2008) Oat: unique among the cereals. Eur J Nutr 47, 68-79.

2. Welch RW (2011) Nutrient composition and nutritional quality of oats and comparisons with other cereals. In Oats: Chemistry and Technology, pp. 95-107 [FH Webster and PJ Wood, editors]. St Paul, MN: AACC International Inc.

3. Webster FH (2011) Oat utilization: past, present and future. In Oats: Chemistry and Technology, 2nd ed., pp. 347-361 [FH Webster and PJ Wood, editors]. St Paul, MN: AACC International Inc.

4. Whitehead A, Beck EJ, Tosh S, et al. (2014) Cholesterollowering effects of oat $\beta$-glucan: a meta-analysis of randomized controlled trials. Am J Clin Nutr 100, 1413-1421.

5. Tosh SM (2013) Review of human studies investigating the post-prandial blood-glucose lowering ability of oat and barley food products. Eur J Clin Nutr 67, 310-317.

6. Giradet N \& Webster FH (2011) Oat milling: specifications, storage, and processing. In Oats: Chemistry and Technology, 2nd ed., pp. 301-302 [FH Webster and PJ Wood, editors]. St Paul, MN: American Association of Cereal Chemists.

7. Fast RB \& Caldwell EF (2000) Breakfast Cereals and How They Are Made, 2nd ed. St Paul, MN: American Association of Cereal Chemists.

8. Miller SS (2011) Microstructure and chemistry of the oat kernel. In Oats: Chemistry and Technology, 2nd ed., pp. 77-94 [FH Webster and PJ Wood, editors]. St Paul, MN: American Association of Cereal Chemists.

9. Yiu SH, Wood PJ \& Weisz J (1987) Effects of cooking on starch and beta-glucan of rolled oats. Cereal Chem 68, 373-379.

10. Yiu SH, Weisz J \& Wood PJ (1991) Comparison of the effects of microwave and conventional cooking on starch and beta-glucan in rolled oats. Cereal Chem 68, 372-379.

11. Wolever TMS, Vorster HH, Björck I, et al. (2003) Determination of the glycaemic index of foods: interlaboratory study. Eur J Clin Nutr 57, 475-482.

12. University of Sydney (2011) Glycemic index. http://www. glycemicindex.com (accessed December 2014).

13. Baker IDI Heart \& Diabetes Institute (2014) www.bakeridi. edu.au/ (accessed March 2014).

14. GI Laboratories (2014) www.gilabs.com/ (accessed December 2014).

15. Aston LM, Gambell JM, Lee DM, et al. (2008) Determination of the glycaemic index of various staple carbohydrate-rich foods in the UK diet. Eur J Clin Nutr 62, 279-285.

16. Jenkins DJ, Wolever TM, Taylor RH, et al. (1981) Glycemic index of foods: a physiological basis for carbohydrate exchange. Am J Clin Nutr 34, 362-366.
17. Connolly ML, Tuohy KM \& Lovegrove JA (2012) Wholegrain oat-based cereals have prebiotic potential and low glycaemic index. Br J Nutr 108, 2198-2206.

18. Granfeldt Y, Eliasson AC \& Björck I (2000) An examination of the possibility of lowering the glycemic index of oat and barley flakes by minimal processing. J Nutr 130, 2207-2214.

19. Brand Miller J, Pang E \& Bramall L (1992) Rice: a high or low glycemic index food? Am J Clin Nutr 56, 1034-1036.

20. Venter CS, Jerling JC, van Heerden Y, et al. (2005) More evidence for capillary sampling in the determination of glycaemic index. South Afr J Clin Nutr 18, 238-242.

21. Henry CJK, Lightowler HJ, Strik CM, et al. (2005) Glycaemic index and glycaemic load values of commercially available products in the UK. BrJ Nutr 94, 922-930.

22. Granfeldt Y, Hagander B \& Bjorck I (1995) Metabolic responses to starch in oat and wheat products. On the importance of food structure, incomplete gelatinization or presence of viscous dietary fibre. Eur J Clin Nutr 49, 189-199.

23. Krezowski PA, Nuttall FQ, Gannon MC, et al. (1987) Insulin and glucose responses to various starch-containing foods in type II diabetic subjects. Diabetes Care 10, 205-212.

24. Hätönen KA, Similä ME, Virtamo JR, et al. (2006) Methodologic considerations in the measurement of glycemic index: glycemic response to rye bread, oatmeal porridge, and mashed potato. Am J Clin Nutr 84, 1055-1061.

25. Wolever TMS, Katzman-Relle L, Jenkins AL, et al. (1994) Glycaemic index of 102 complex carbohydrate foods in patients with diabetes. Nutr Res 14, 651-669.

26. Wolever TMS, Wong GS, Kenshole A, et al. (1985) Lactose in the diabetic diet: a comparison with other carbohydrates. Nutr Res 5, 1335-1345.

27. Lok KY, Chan R, Chan D, et al. (2010) Glycaemic index and glycaemic load values of a selection of popular foods consumed in Hong Kong. Br J Nutr 103, 556-560.

28. Yang YX, Wang HW, Cui HM, et al. (2006) Glycemic index of cereals and tubers produced in China. World J Gastroenterol 12, 3430-3433.

29. Henry CJK, Lightowler HJ, Dodwell LM, et al. (2007) Glycaemic index and glycaemic load values of cereal products and weight-management meals available in the UK. BrJ Nutr 98, $147-153$.

30. Holt S, Brand J, Soveny C, et al. (1992) Relationship of satiety to postprandial glycaemic, insulin and cholecystokinin responses. Appetite 18, 129-141.

31. Perry T, Mann J, Mehalski K, et al. (2000) Glycaemic index of New Zealand foods. $N Z$ Med J 113, 140-142.

32. Zafar TA, Kabir Y \& Ghazaii C (2011) Low glycemic index foods suppress glycemie response, appetite and food intake in young Kuwaiti females. Kuwait J Sci Eng 38, 111-123.

33. Jenkins DJA, Wolever TMS, Jenkins AL, et al. (1983) The glycaemic index of foods tested in diabetic patients: a new basis for carbohydrate exchange favouring the use of legumes. Diabetologia 24, 257-264.

34. Brand-Miller J, Pang E \& Broomhead L (1995) The glycaemic index of foods containing sugars: comparison of foods with naturally-occurring v. added sugars. Br J Nutr 73, 613-623.

35. Englyst KN, Vinoy S, Englyst HN, et al. (2003) Glycaemic index of cereal products explained by their content of rapidly and slowly available glucose. Br J Nutr 89, 329-339.

36. Jenkins AL, Kacinik V, Lyon M, et al. (2010) Effect of adding the novel fiber, PGX ${ }^{\circledR}$, to commonly consumed foods on glycemic response, glycemic index and GRIP: a simple and effective strategy for reducing post prandial blood glucose levels - a randomized, controlled trial. Nutr J 9, 58. 
37. Wolever TMS (2006) The Glycaemic Index: A Physiological Classification of Dietary Carbohydrate. Cambridge, MA: CABI.

38. Doehlert DC, Simsek S, Thavarajah D, et al. (2013) Detailed composition analyses of diverse oat genotype kernels grown in different environments in North Dakota. Cereal Chem 90, $572-578$.
39. USDA (2013) United States Department of Agriculture National Nutrient Database for Standard Reference. http://ndb.nal.usda.gov/ (accessed March 2014).

40. Foster-Powell K, Holt SH \& Brand-Miller JC (2002) International table of glycemic index and glycemic load values: 2002. Am J Clin Nutr 76, 5-56. 